\title{
NEUTRALIZAÇÃO DA VOGAL PRETÔNICA E FORMAÇÃO DE PALAVRAS EM PORTUGUÊS BRASILEIRO $^{1}$
}

\author{
PRETONIC VOWEL NEUTRALIZATION AND WORD FORMATION \\ IN BRAZILIAN PORTUGUESE
}

Luiz Carlos Schwindt ${ }^{2}$

Resumo: Neste texto, na perspectiva da Fonologia Prosódica (Selkirk, 1984, 1996; Nespor e Vogel, 1986), tratamos da relação entre neutralização da vogal pretônica e processos de derivação e composição em português brasileiro (PB). Interpretamos as possibilidades de representação de um arquifonema propostas por Trubetzkoy para defender que a neutralização produz uma consequente redução no inventário fonológico da língua, que passa de 7 a 5 segmentos vocálicos, em moldes semelhantes aos sugeridos por Camara Jr. (1977). A partir disso, procuramos evidências para sustentar a associação entre acento primário e superficialização de vogal média-baixa em determinados dialetos do $P B$ e para a consequente demarcação de fronteira de palavra fonológica. A análise contribuiu para confirmar a classificação de alguns afixos descritos na literatura como palavras fonológicas independentes, à semelhança das bases envolvidas na composição (conf. Schwindt 2000; Bisol, 2004). Trazemos, ainda, argumentos adicionais para defender igual status prosódico aos sufixos inho e zinho, garantindo a interpretação de alomorfia fonologicamente condicionada (conf. Bisol, 2010).

Palavras-chave: neutralização, formação de palavras, palavra fonológica, morfofonologia

\begin{abstract}
In this paper, from the perspective of Prosodic Phonology (Selkirk 1984, 1996, Nespor and Vogel, 1986), we deal with the relationship between neutralization of pretonic vowels and word formation - particularly derivation and composition - in Brazilian Portuguese (BP). We call the Trubetzkoy's approach for choice of archiphonemes' representatives to argue that the neutralization produces a consequent reduction in the phonological inventory

1 Agradeço a leitura atenta e os comentários de Leda Bisol e Gisela Collischonn. Quaisquer equívocos, porém, são de minha responsabilidade. Agradeço também às bolsistas de Iniciação Científica Camila Witt Ulrich e Thiely Andressa Schwingel pelo competente envolvimento na análise empírica que apresentamos parcialmente aqui.

2 Professor do Instituto de Letras da UFRGS, pesquisador do CNPq.
\end{abstract}


of vowels in BP, from 7 to 5 segments, similarly to the analysis proposed by Camara Jr. (1977). From this, we bring evidences to support the association between main stress and superficial realization of open-medium vowels in certain BP dialects, which allows us to delimit boundaries of phonological words. This analysis helped to confirm the classification of some affixes described in the literature as independent phonological words, similarly to the bases involved in composition (cf. Schwindt 2000; Bisol, 2004). Furthermore, empirical arguments have been joined to defend an equal prosodic status for the suffixes inho and zinho, ensuring the interpretation of phonologically conditioned allomorphy (cf. Bisol, 2010).

Keywords: neutralization, word formation, phonological word, morphophonology

\section{Introdução}

Neste artigo, propõe-se uma abordagem morfofonológica dos processos de formação de palavras em português brasileiro (PB), considerando especificamente um processo bastante produtivo na fonologia da língua, a neutralização das vogais médias em posição pretônica (ex. $m[\varepsilon]$ dico $>m[e]$ dicina, mas $m[\varepsilon]$ dicozinho; $s[\supset] l>s[o] l a c ̧ o$, mas $s[\supset] l z i n h o)$. O objetivo é discutir o estatuto prosódico das bases envolvidas na formação de palavras derivadas (prefixadas e sufixadas) e na composição. O processo de neutralização da vogal pretônica (NVP), nesse quesito, mostra-se particularmente informativo se considerarmos que a manutenção de vogais médias-baixas é indicativo de presença de acento categoricamente em dialetos do sul e do sudeste - critério limitador de palavras fonológicas (PWds), considerando-se as perspectivas de Selkirk (1984) e Nespor e Vogel (1986)

Para dar conta desse objetivo, apresenta-se um panorama da neutralização em PB, considerando a abordagem de Câmara Jr. (1977) e a concepção de Trubetzkoy ([1939]1969), e discutindo brevemente seu comportamento em diferentes dialetos do PB; na seção 3, apresentam-se dados de derivação e de composição envolvendo o processo de NVP; na seção 4, propõem-se configurações prosódicas sustentadas por essa análise; as conclusões são apresentadas, por fim, na seção 5 .

\section{Neutralização da vogal pretônica no português brasileiro}

O português, como descrito por Câmara Jr. (1977), Wetzels (1992), Mateus e D’andrade (2000) e Bisol (2003, 2004), entre diversos outros,

3 A sigla PWd que equivale à expressão Prosodic (or Phonological) Word, em inglês. 
caracteriza-se por um sistema de 7 oposições vocálicas em posição tônica, reduzindo-se a 5 na pauta pretônica e a 3 na pauta postônica final. ${ }^{4}$

(1) Sistema vocálico do PB (adaptado de Camara Jr., 1977)

\section{posição pretônica}

i

e, $\varepsilon$

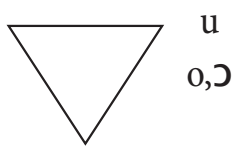

a

$\mathrm{m}[\mathrm{i}] \mathrm{rar}$

$\mathrm{m}[\mathrm{u}] \mathrm{rar}$

$\mathrm{m}[\mathrm{e}] \mathrm{lar} \sim \mathrm{m}[\varepsilon] \mathrm{lar}$

$\mathrm{m}[\mathrm{o}] \mathrm{lar} \sim \mathrm{m}[\mathrm{J}] \mathrm{lar}$

$\mathrm{m}[\mathrm{a}] \mathrm{lar}$ posição tônica

i

e

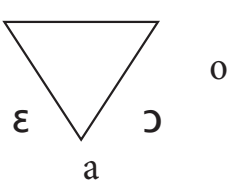

s[i]lo

$\mathrm{s}[\mathrm{u}] \mathrm{co}$

$\mathrm{s}[\mathrm{e}] \mathrm{co}$

$\mathrm{s}[\varepsilon] \mathrm{co}$

$\mathrm{s}[\mathrm{o}] \mathrm{co}$

$\mathrm{s}[\mathrm{J}] \mathrm{co}$

$\mathrm{s}[\mathrm{a}] \mathrm{co}$ posição postônica final

$\mathrm{u}$

$\mathrm{i}, \mathrm{e}$

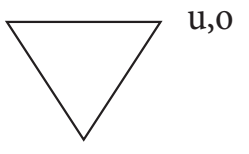

a

$\mathrm{fal}[\mathrm{I}] \sim \mathrm{fal}[\mathrm{e}]$

$\mathrm{fal}[\mathrm{U}] \sim \mathrm{fal}[\mathrm{o}]$

$\mathrm{fal}[\mathrm{e}]$

Em relação aos exemplos em (1), queremos chamar atenção para o fato de que, em $\mathrm{PB}$, na posição pretônica, podem-se ouvir pronúncias tanto com vogal média-alta quanto com vogal média-baixa, a depender do dialeto e do contexto fonológico em questão. Assim, é comum que em cidades do norte ou do nordeste do Brasil, conforme exemplificado acima, escutem-se pronúncias como $m[\varepsilon]$ lar ou $m[\supset]$ lar, em lugar de $m[e] l a r$ ou $m[o] l a r$. Trata-se de variação, sem qualquer efeito distintivo, que se aplica mais ou menos preponderantemente em certas regiões e em certos contextos fonológicos. Contudo, em outros dialetos, como do sul e do sudeste, os quais abordamos mais diretamente aqui, observa-se, de forma geral, um emprego categórico de vogais médias-altas nesses mesmos ambientes. ${ }^{5}$

Um exemplo bastante ilustrativo, que problematiza e, ao mesmo tempo, reforça a ideia de que de fato não há oposição entre vogais médias na pauta pretônica é o emprego produtivo de alguns supostos pares mínimos na lín-

4 Optamos por não incluir as características da posição postônica medial nessa exposição, por não ser crucial para o argumento que aqui se desenvolve. Sobre o tema, sugere-se ver Vieira (2002) e Bisol (2004).

5 Fica claro, aqui, que não optamos por tratar a oposição que abordamos aqui como gradual, isto é, uma oposição que levasse em conta as séries /i,e,E/, /u,o,J/. Isso se deve ao fato de considerarmos que, pela natureza dos processos implicados, estamos diante de uma oposição privativa, que opõe a vogal média-alta à realização como média-baixa e como alta, cada uma a seu tempo. Ademais, há boas razões para não se entender, nos termos aqui explorados, a oposição $e / i, o / u$, na pauta pretônica, como neutralização em português, haja vista haver, inclusive, alguns pares mínimos envolvendo esses sons, como [e]migrar vs. [i]migrar ou $m[o]$ rar vs. $m[u] r a r$, o que nos impediria de associar a neutralização de que tratamos neste texto a um contexto puramente acentual. 
gua, como $\operatorname{pr}[e]$ conceito $v s . \operatorname{pr}[\varepsilon]$ conceito, em que a segunda forma, a com vogal média-baixa, tem sentido prefixal transparente (de conceito anterior, prévio). Retomaremos esse exemplo adiante, quando tratarmos de formas derivadas, mas sublinhamos de partida nossa primeira interpretação do fato linguístico nele implicado: admitimos que, na primeira pronúncia, a vogal [e] é, de fato, pretônica, ao passo que a vogal [ $\varepsilon$ ], na segunda pronúncia, deve ser considerada tônica. Sendo assim, a hipótese da neutralização é preservada: aplica-se no primeiro caso, mas não tem contexto para se aplicar no segundo.

Se queremos, porém, analisar a língua portuguesa falada no Brasil como um único sistema, precisamos dar conta do fato de que a neutralização tem efeitos de superfície diferentes em certas variedades da língua, ou seja, elege categoricamente uma entre as duas variantes vocálicas em alguns dialetos, mas admite variação em outros.

O tratamento dessa questão começa pela própria definição de neutralização que se assume na análise. Em primeiro lugar, é preciso distinguir-se neutralização de variação, como observam Callou e Leite:

Dentro do estruturalismo europeu, temos de lembrar ainda o conceito de neutralização, que não deve ser confundido com o de variação. Existe neutralização quando há uma supressão da oposição entre dois ou mais fonemas em determinados contextos, isto é, quando uma oposição é anulada ou neutralizada. No sistema fonológico do português,

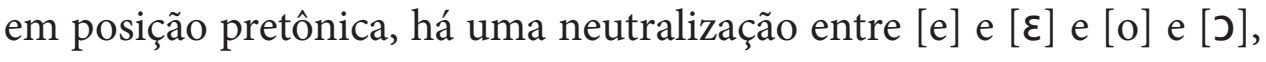
cuja oposição é funcional em posição tônica. Em posição átona os dois fonemas correlativos tornam-se intercambiáveis sem que isso altere o significado da forma. (...) Lembrando a distinção do linguista Eugenio Coseriu entre sistema - norma - fala, vale observar que a realização é indiferente do ponto de vista do sistema funcional mas poucas vezes será distinta do ponto de vista da norma. No Rio de Janeiro e no Sul do país, em geral, esse arquifonema será realizado com timbre mais fechado, [e] ou [o], enquanto no Nordeste o timbre aberto ocorre com maior freqüência, $[\varepsilon]$ e $[\supset]$. As normas variam, portanto, de região, para região. (1990:42)

Muitos são os autores que discutiram o status variável das vogais médias pretônicas em diferentes perspectivas e considerando diferentes dialetos, entre eles Bisol (1981), Viegas (1987), Silva (1989), Callou, Leite e Coutinho (1991), Lee (2003, 2004, 2012), Schwindt (1995, 2002), entre inúmeros outros. Não nos deteremos nessas análises neste artigo, contu- 
do, por a variação propriamente dita não constituir foco central em nossa discussão. Também não temos a intenção de discutir neutralização per se. Nosso propósito é problematizar a relação entre o comportamento das vogas médias em posição pretônica e processos de formação de palavras em português brasileiro. Os temas variação e neutralização serão chamados tão somente na medida desse propósito.

Uma primeira questão que, apesar de secundária, impõe-se nessa discussão é a de como formalizar o fenômeno de neutralização, isto é, é preciso se definir qual a unidade do sistema que subjaz o processo de neutralização - e isso está na dependência da concepção teórica que se assume.

$\mathrm{Na}$ concepção distribucionalista norte-americana, de caráter precipuamente sintagmático, a tendência seria a de se eleger um dos segmentos concorrentes como o fonema, mas isso esbarra na violação da máxima uma vez fonema, sempre fonema, já que o mesmo segmento que é fonema na pauta tônica se reduz a alofone de outro fonema na pauta pretônica (gerando uma sobreposição alofônica). Uma solução, proposta pela Escola de Praga, foi a proposição do arquifonema, uma realização não marcada da neutralização: "By the term 'archiphoneme' we understand the sum of distinctive properties that two phonemes have in commom" (Trubetzkoy, [1939]1969:79). Para Trubetzkoy, a neutralização, assim, tinha de se estabelecer entre dois elementos (ou bilateralmente), isto é, os traços especificados tinham de conduzir a apenas um par neutralizável na língua, que se definiria pela especificação do traço em aberto.

Para dar conta de como o arquifonema se realiza nas línguas, Trubetzkoy (op. cit.:79-83) propôs quatro casos, a seguir resumidos.

No caso I, o representante do arquifonema não é idêntico a nenhum dos membros da oposição. Nesse caso, o fone que ocorre na posição de neutralização é uma variante de um ou de outro membro da oposição - ou de ambos.

No caso II, o representante do arquifonema é idêntico a um dos membros da oposição, sendo a escolha motivada externamente. Isso ocorre quando a neutralização está na dependência da proximidade fonológica de algum som vizinho ao ambiente da neutralização.

No caso III, o representante do arquifonema também é idêntico a um dos membros da oposição, como no caso II, mas a escolha é motivada internamente, isto é, sua escolha não está relacionada à natureza de sua posição. $\mathrm{O}$ fone que se realiza no contexto de neutralização é considerado não marcado em contraste ao outro elemento, considerado marcado.

No caso IV, ambos os membros da oposição representam o arquifonema - o primeiro em um contexto e o segundo em outro contexto da posi- 
ção de neutralização. Trata-se, na maioria dos casos, de uma combinação entre os casos II e III, pois em geral estão envolvidos condicionamento externo e interno nesse tipo de neutralização.

Segundo Trubetzkoy, ainda que o caso I seja bastante comum, é o caso III o mais encontrado nas línguas em geral; o caso II e a versão pura do caso IV são descritas como mais raras pelo autor.

A pergunta que se coloca para a reflexão que se promove neste texto é: se assumíssemos essa perspectiva, em qual desses casos se enquadraria a neutralização da vogal pretônica em português brasileiro?

A resposta não é tão simples, porque depende de diferentes critérios. Para se excluir I, é preciso se defender que, de fato, neste contexto, ou se realiza a vogal média-alta ou se realiza a vogal média-baixa, eliminando-se, neste caso, qualquer outra realização intermediária que possa figurar aí. Essa seria uma análise a ser considerada para a posição postônica final, em que o elemento fonético que se realiza na maior parte dos dialetos é uma vogal reduzida, ou seja, uma vogal distinta - ainda que compartilhando propriedades - do par envolvido na neutralização (vogal alta e vogal média-alta). Por outro lado, tal hipótese não parece sustentável para a oposição média-alta/média-baixa em posição pretônica, ao menos de um ponto de vista perceptual. Em relação aos demais casos, contudo, para excluí-los ou sustentá-los, seria necessário antes de mais nada se decidir sobre analisar o PB como um só sistema ou como diferentes sistemas nesse quesito. Isso porque, como afirmamos anteriormente, a variação entre as médias alta e baixa parece ser mais forte entre dialetos do que intradialetalmente - ou, pelo menos, pode-se afirmar que nos dialetos que optam por realizar uma vogal média-alta não parece haver variação significativa, exceto nos casos de harmonia "para cima", isto é, de harmonia promovida pela vogal alta. Contudo, nos dialetos em que vogais médias-baixas se manifestam em posição pretônica pode haver indícios do caso II, ou seja, de processos assimilatórios que repercutam no abaixamento dessas vogais, à semelhança da tão disseminada harmonia vocálica, que, ao contrário, promove alteamento da pretônica sob determinadas condições contextuais, conforme Bisol (1981), Silva (1989), Callou, Leite e Coutinho (1991), Schwindt (1995), entre diversos outros. ${ }^{6} \mathrm{O}$ caso III não nos parece problemático para incluir o

6 Não desenvolvemos aqui os argumentos para sustentar o processo de abaixamento a que estamos nos referindo, uma vez que escapam aos propósitos deste artigo, mas sinalizamos, entre outros motivadores, para a forte influência da presença de vogais baixas ou médiasbaixas em posição subsequente à pretônica nesses casos - o que poderia apontar para um processo de assimilação regressiva, nos mesmos moldes da harmonia da vogal alta. 
fenômeno de neutralização em questão, se admitirmos que o representante do arquifonema é um dos dois segmentos, e que a motivação para isso é interna, caracterizando um contraste de marcação, no termos de Trubetzkoy. Isso, porém, só pode ser válido intradialetalmente no caso do $\mathrm{PB}$, ou seja, se de fato se sustentar empiricamente a hipótese de que no subsistema do sul do país, por exemplo, só ocorre a vogal-média alta nessa posição. Por fim, ainda há a possibilidade de se enquadrar o fenômeno no caso IV, isto é, de se enxergarem os dois elementos como representantes do arquifonema, com um fone não marcado concorrendo com outro que é fruto de assimilação. Isso não parece, entretanto, uma solução para se tratar NVP interdialetalmente: o problema, nesse caso, será se decidir qual fone entre os membros do par é fruto de assimilação (com motivação externa, nos temos de Trubetzkoy), já que, nos dialetos em que ocorre abaixamento de forma geral, a realização da média-alta também pode ser considerada resultado de algum tipo de harmonia (conforme Silva, 1989).

Para dar conta da discussão que queremos tratar neste artigo, qual seja, a da relação entre a neutralização da pretônica e os processos de derivação, é preciso que assumamos a perspectiva de III. Fazemos isso reinterpretando esse caso num viés gerativo, em que a forma subjacente da vogal nesse contexto é sempre média-alta (a que poderia ser interpretada como não marcada quanto à altura, nos termos de Trubetzkoy). Com isso, se considerarmos uma perspectiva segmental, podemos dizer que o inventário fonológico subjacente do português, então, se reduz a 5 elementos na pauta pretônica: /i/, /u/, /e/, /o/, /a/ (o que muito se assemelha à proposta de Camara Jr., 1977, ainda que sua análise não se fundamente nos mesmos termos).

No âmbito da fonologia gerativa, podemos ainda reinterpretar a noção de arquifonema, no caso de NVP, a partir do conceito de subespecificação de traço. Essa análise não entra em contradição com nossa discussão, desde que se entenda a palavra fonológica como domínio do processo (cf. Wetzels, 1992, 1995; Bisol, 1996). Assim, especificada como média-alta ou não completamente especificada em relação à altura/abertura, a vogal só se realizará como média-baixa em posição tônica, configurando, nos termos de Nespor e Vogel (1986), uma nova palavra fonológica, como veremos com maior detalhamento na seção 4 .

\section{Neutralização da pretônica e processos de formação de palavras}

O processo de NVP pode ser mais claramente evidenciado quando se formam novas palavras, ou seja, quanto a palavra é aumentada por outros 
morfemas (afixos ou radicais). Isso é assim porque esse aumento gera deslocamento do acento primário, que, em português, aloca-se numa janela de até três sílabas da direita para a esquerda da palavra. Ora, se o acento se desloca, espera-se que vogais médias-baixas originalmente tônicas convertam-se em médias-altas ao se tornarem pretônicas (ex. $m[\varepsilon]$ dico $>$ $m[e]$ dicina $)^{7}$

Vamos nos fixar, aqui, em casos em que a vogal se mantém necessariamente média-baixa nos dialetos a que me referi antes, que assumem essa redução do inventário também em nível de superfície, para discutir os limites prosódicos que se pareiam às unidades mórficas envolvidas nessas formações.

(2) Palavras complexas em PB e a NVP

\begin{tabular}{|c|c|c|c|c|c|}
\hline a. Prefixação & & b. Sufixação & & c. Composição & \\
\hline $\operatorname{pr}[\varepsilon]$-escola & pr[e]dição & $\mathrm{t}[\varepsilon]$ linha & $\mathrm{t}[\mathrm{e}] \mathrm{lão}$ & {$[\varepsilon]$ co-turismo } & [e]cologia \\
\hline $\mathrm{n}[\varepsilon] \mathrm{o}$-doutor & $\mathrm{n}[\mathrm{e}]$ ologismo & $\operatorname{caf}[\varepsilon]$ zinho & caf[e]ína & $\mathrm{m}[\varepsilon]$ todologia & $\mathrm{m}[\mathrm{e}]$ tódico \\
\hline $\mathrm{p}[\mathrm{J}] \mathrm{s}$-parto & $\mathrm{p}[\mathrm{o}]$ sposto & $\begin{array}{c}\mathrm{b}[\varepsilon] \text { líssimo } \\
\mathrm{f}[\mathrm{J}] \text { rtemente } \\
\text { s[J]lzinho }\end{array}$ & $\begin{array}{c}\text { b[e]leza } \\
\text { f[o]rtaleza } \\
\text { s[o]laço }\end{array}$ & $\begin{array}{c}\mathrm{p}[\supset] \mathrm{rta}-\mathrm{bandeira} \\
\mathrm{b}[\supset] \mathrm{la}-\mathrm{f}[\mathrm{J}] \mathrm{ra}\end{array}$ & $\begin{array}{l}\mathrm{p}[\mathrm{o}] \mathrm{rtal} \\
\mathrm{b}[\mathrm{o}] \text { leiro }\end{array}$ \\
\hline
\end{tabular}

Nos exemplos (2a), (2b) e (2c), acima, todos de palavras derivadas formadas a partir de uma palavra primitiva contendo vogal média-baixa, observa-se um comportamento distinto entre as palavras da coluna da esquerda e as palavras da coluna da direita em cada processo. As da esquerda mantêm a vogal média-baixa, enquanto as da direita a convertem numa vogal média-alta. Como dissemos anteriormente, nos dialetos que estamos descrevendo, essa alteração é categórica, ou seja, postula-se que mudar a qualidade da vogal, aqui, quando possível, no mínimo produz uma nova nuança de significado na língua, sinalizada por maior ou menor transparência dos limites morfológicos, como ilustramos anteriormente com o par $\operatorname{pr}[e]$ conceito / pr $[\varepsilon]$ conceito. ${ }^{8}$

No caso da prefixação (exemplos de (2a)), o aumento da palavra à es-

7 Para uma descrição mais abrangente de dados de neutralização da pretônica e de formação de palavras em PB, sugerimos ver Quadros e Schwindt (2008). Nesse estudo, o fenômeno é descrito e problematizado a partir de dados do Projeto VARSUL (Variação Linguística na Região Sul do Brasil) e de um instrumento de leitura aplicado a informantes porto-alegrenses.

8 Consideramos temerário se afirmar que palavras derivadas com vogal média-alta não são transparentes sincronicamente. Optamos por afirmar tão somente que casos como $\operatorname{pr}[\varepsilon] v e r$ / $\operatorname{pr}[e] v e r$ estão em posições diferentes no contínuo de produtividade/transparência morfológica da língua, nos termos de Aronoff (1976), em que a primeira é mais produtiva/transparente do que a segunda. Em Schwindt (2002; 2008a,b), apresentamos um interpretação da noção de produtividade numa perspectiva prosódico-lexical e prosódico-otimalista, respectivamente.

Organon, Porto Alegre, v. 28, n. 54, p. 137-154, jan./jun. 2013. 
querda da base não produz efeitos sobre o acento dessa base. Isso, porém, não afeta a hipótese que perseguimos aqui; ao se manter a vogal média-baixa no prefixo (como pre) e uma base com vogal acentuada (inclusive também com vogal média-baixa, como escวla), assumimos que tais palavras possuem dois acentos principais.

A sufixação (exemplificada em (2b)), diferentemente da prefixação, por representar um aumento à direita da base, tem repercussão sobre a atribuição do acento, isto é, de forma geral, se um sufixo for dissilábico, para atender ao padrão paroxítono do português, o acento incidirá sobre ele (como em solaço, em que o acento se desloca para a direita e recai sobre o $a$, primeira sílaba de que o sufixo faz parte). A consequência interessante disso é que, nos dialetos (ou na noção de sistema subjacente) em que apoiamos essa argumentação, a vogal da base, que era média-baixa, se converte categoricamente em média-alta, como efeito de NVP. Em outras palavras: nesses dialetos a pronúncia səlaço não se licencia. Isso, contudo, como se atesta amplamente na literatura, não acontece com palavras sufixadas por inho, zinho, mente e íssimo, afixos que, apesar de se comportarem igualmente aos demais em relação ao acento (também respeitam a janela de três sílabas, convergindo para o acento paroxítono - ou se preserva proparoxítono, no caso de íssimo), têm a propriedade de manter as bases a que se ligam inalteradas no que concerne à altura de suas vogais, como em tela $>t \varepsilon l i n h a, s \supset l>s \supset l z i n h o$. À semelhança da análise que sugerimos para os vocábulos prefixados a que nos referimos acima, somos levados a entender que as palavras derivadas por esses sufixos também possuem dois acentos.

No caso da composição, exemplificada em (2c), constata-se o mesmo que se observa na derivação: se assumimos o argumento de que a cada vogal média-baixa temos uma proeminência, podemos sustentar que também na composição mantêm-se dois acentos. ${ }^{9}$

A relação entre NVP e os processos de formação exemplificados em (2) levam à inquestionável tese de que fonologia e morfologia se relacionam

9 O curioso, no caso da composição, é que a abertura da vogal pode se conservar mesmo em casos em que as formas não são absolutamente transparentes em termos morfológicos, como em mEritocracia, em cujo emprego provavelmente o falante não recupera os sentidos das bases. Quadros e Schwindt (2008) observaram, contudo, que, em tais casos, no mais das vezes, ao menos uma das duas bases envolvidas pode ser considerada livre. Se considerarmos o princípio de exaustividade associado à Strict Layer Hypotesis (cf. Nespor e Vogel,1986), podemos dizer que, nesse caso, a identificação de um limite prosódico força a escansão do que está fora dele também como palavra prosódica. Nesse caso, uma das palavras prosódicas envolvidas no composto poderia não coincidir, em termos de mapeamento, com uma palavra morfológica. 
em algum nível da gramática, como preconizou, por exemplo, a Fonologia e Morfologia Lexical (Kiparsky, 1982, 1985; Mohanan, 1982, 1985), mas como também se pode garantir numa perspectiva de restrições, como a Teoria da Otimidade (TO), quando se admite conspiração de restrições que tomam como domínio contextos prosódicos e morfológicos.

\section{A prosodização de palavras derivadas e compostas envolvendo NVP em PB}

Não se pode assegurar isomorfismo perfeito nas línguas do mundo entre estruturas morfológicas e prosódicas. Isso pode ser bem ilustrado com o clássico exemplo de Booij e Lieber (1989) para a palavra unhappier em inglês. Conforme se pode ver em (3), a seguir, para atender à exigência prosódica de que palavras sejam maximamente dissilábicas para receber o sufixo comparativo er, tem-se de admitir que sufixação precede prefixação na construção da palavra. Por outro lado, do ponto de vista morfológico, dado o escopo de negação do prefixo un, que, neste caso, parece se associar à forma ainda não sufixada ([mais [não feliz]]; ${ }^{*}[$ não [mais feliz]]/), somos forçados a admitir a precedência da prefixação.

(3) Morfologia em tandem (adaptado de Booij e Lieber, 1989)

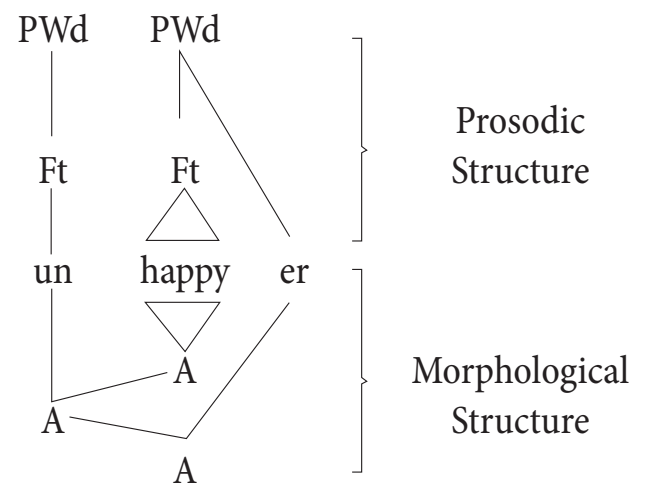

O não isomorfismo entre estruturas fonológicas e morfológicas ou sintáticas foi constatado por muitos linguistas de diferentes correntes teóricas e descritivas, o que contribui para a proposição de hierarquias prosódicas independentes de hierarquias gramaticais (cf. Liberman e Prince, 1977; Selkirk, 1982; Nespor e Vogel, 1986; Inkelas, 1989, entre outros).

Para solucionar o impasse constatado em (3), Booij e Lieber (1989) propõem que un e a base happier constituam diferentes palavras fonológicas abarcadas pelo mesmo elemento morfossintático. 
A decisão, contudo, de que determinados afixos constituem palavras fonológicas independentes numa língua não é trivial. Para Nespor e Vogel (1986), a palavra fonológica é o componente da hierarquia prosódica que domina imediatamente o pé e é dominado pelo grupo clítico. Por dominar o pé caracteriza-se, naturalmente, como o domínio do acento primário. Isso, contudo, não impõe necessariamente que todas as PWds devam ser acentuadas, mas, por outro lado, exclui desse rótulo estruturas com mais de um acento primário atribuído. Em outras palavras, não é possível haver duas estruturas com igual proeminência sob o rótulo de PWd (dois pés fortes).

Se recuperamos a tese defendida neste artigo, qual seja a de que a neutralização da vogal pretônica em português brasileiro tem como consequência a redução do inventário de segmentos possíveis em posição átona, restringindo vogais médias-baixas fonológicas exclusivamente à posição tônica, somos forçados a admitir que a cada realização de uma vogal média-baixa, estamos diante de uma nova PWd. Caso contrário, vocábulos como $\operatorname{pr}[\varepsilon]$-esc[J]la ou $b[\supset] l a-f[\supset] r a$ estariam contrariando a exigência de uma só proeminência por palavra, já que são constituídas de duas vogais médias-baixas cada uma (ou de duas proeminências acentuais, nos termos do que se defende neste artigo).

No caso dos sufixos, isso é menos evidente. Apesar de termos alguns sufixos que se apresentam com vogais médias-baixas em português (como -tório, -érrimo, -ésimo), as bases também com vogal média-baixa a que a eles se associam parecem estar sujeitas a neutralização da pretônica (ex. $m[e] r i$ tório, pr[o]spérrimo, f[o]rtésimo), da mesma forma que a maioria dos sufixos da língua (sem vogal média-baixa). Contudo, com os sufixos -inho, -zinho e -íssimo, por exemplo, a neutralização não se aplica. Se considerarmos a janela de três sílabas imposta sobre o acento na língua, veremos que a análise das formações com esses afixos deve ser a mesma da que dedicamos aos prefixos $\operatorname{pr}[\varepsilon]$ e $p[\supset] s$ : em vocábulos como $t[\varepsilon]$ linha, s[د]lzinho, f[J]rtemente ou $b[\varepsilon]$ líssimo, somos levados a concluir que estamos diante de estruturas constituídas, cada qual, de duas PWds - uma imposta pelo acento na janela de três sílabas; outra imposta pela presença de vogal média-baixa.

Um contraditor poderia defender, por exemplo, que nos casos de afixação acima tratados não há a rigor duas PWds, mas uma estrutura menor do que a palavra combinada a uma base que é palavra (num mecanismo de adjunção prosódica). Essa tese, porém, encontra problemas numa análise de fonologia prosódica padrão, já que contraria a Strict Layer Hypothesis (SLH) - hipótese que reúne princípios que governam a boa formação de estruturas prosódicas, proposta por Nespor e Vogel (1986). Segundo SLH, 
dois nós irmãos devem obrigatoriamente ser de mesma categoria, o que condena representações como as de (4), a seguir. ${ }^{10}$

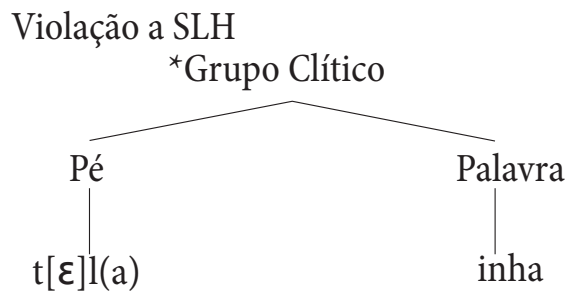

Outro contraditor poderia propor, ainda, a despeito dos argumentos distribucionais que apresentamos na seção anterior, que não há, de fato, duas PWds nos casos de afixação aqui discutidos, supondo que, mesmo nos dialetos que descrevemos, trata-se tão somente de variação na abertura das vogais, um efeito de superfície (como sugerimos anteriormente para alguns dialetos do norte e do nordeste do Brasil). Apesar de nossa convicção de que a análise fonológica subjaz qualquer comportamento foneticamente detectável, para descartar tal hipótese examinamos, acusticamente, pelo programa PRAAT, produções de 8 informantes, cada um pronunciando 24 vocábulos, incluindo palavras simples constituídas de vogal média-baixa na raiz e formas delas derivadas por dois tipos de sufixação - com sufixos que supúnhamos PWds independentes e sufixos legítimos (átonos). Analisamos um dialeto do $\mathrm{PB}$ que não produz abaixamento da pretônica e que, portanto, só produz vogais médias-baixas com os sufixos que aqui consideramos PWds. Nosso intuito era, tentativamente, comparar o padrão acentual entre as sílabas tradicionalmente entendidas como tônicas e as sílabas tradicionalmente concebidas como pretônicas desses diferentes tipos de formações. Como não se dispõe de uma medida acústica específica para o acento, valemo-nos dos seguintes indicadores: duração e intensidade das sílabas e das vogais envolvidas, bem como F1 e F2 dessas vogais. ${ }^{11}$

10 A Strict Layer Hypothesis tem sido objeto de importante debate desde sua proposição. Muitos autores propõem sua relativização, especialmente no que diz respeito à recursividade e à exaustividade das estruturas prosódicas em determinados níveis de análise (cf. Selkirk, 1996; Peperkamp, 1997; Schwindt, 2000; Vigário, 2001; Bisol, 2003; entre outros). Em Schwindt (2008a), admite-se a violação proposta em (4) em PB para dar conta de adjunção de prefixos que, apesar de inacentuados, não se incorporam à PWd a que associam: [sílaba[PWd]]PWd.

11 Os dados provêm de 8 informantes com escolaridade média ou superior, estratificados por sexo e idade (menos de 30 anos e mais de 50 anos). Os informantes tiveram acesso a um arquivo de powerpoint com as palavras inseridas na frase Diga X pra mim, onde X era um dado da análise. Todas as respostas foram gravadas em gravador digital e submetidas ao Programa PRAAT. O levantamento completo, ainda em análise, conta com 28 palavras, divididas em simples, sufixadas por inho,zinho,mente e sufixadas por outros sufixos derivacionais. Analisaram-se tanto as sílabas pretônica e tônica quanto as vogais envolvidas em isolado. 
Embora não seja o foco principal deste texto, trazemos, a seguir, como argumento subsidiário, um pequeno recorte dessa análise, ilustrado em gráficos que comparam as sílabas do par $b[\varepsilon]$ linho / b[ว]linha a b[e]leza / $b[o] l e i r o$ (com pronúncia monotongada) quanto à duração e à intensidade.

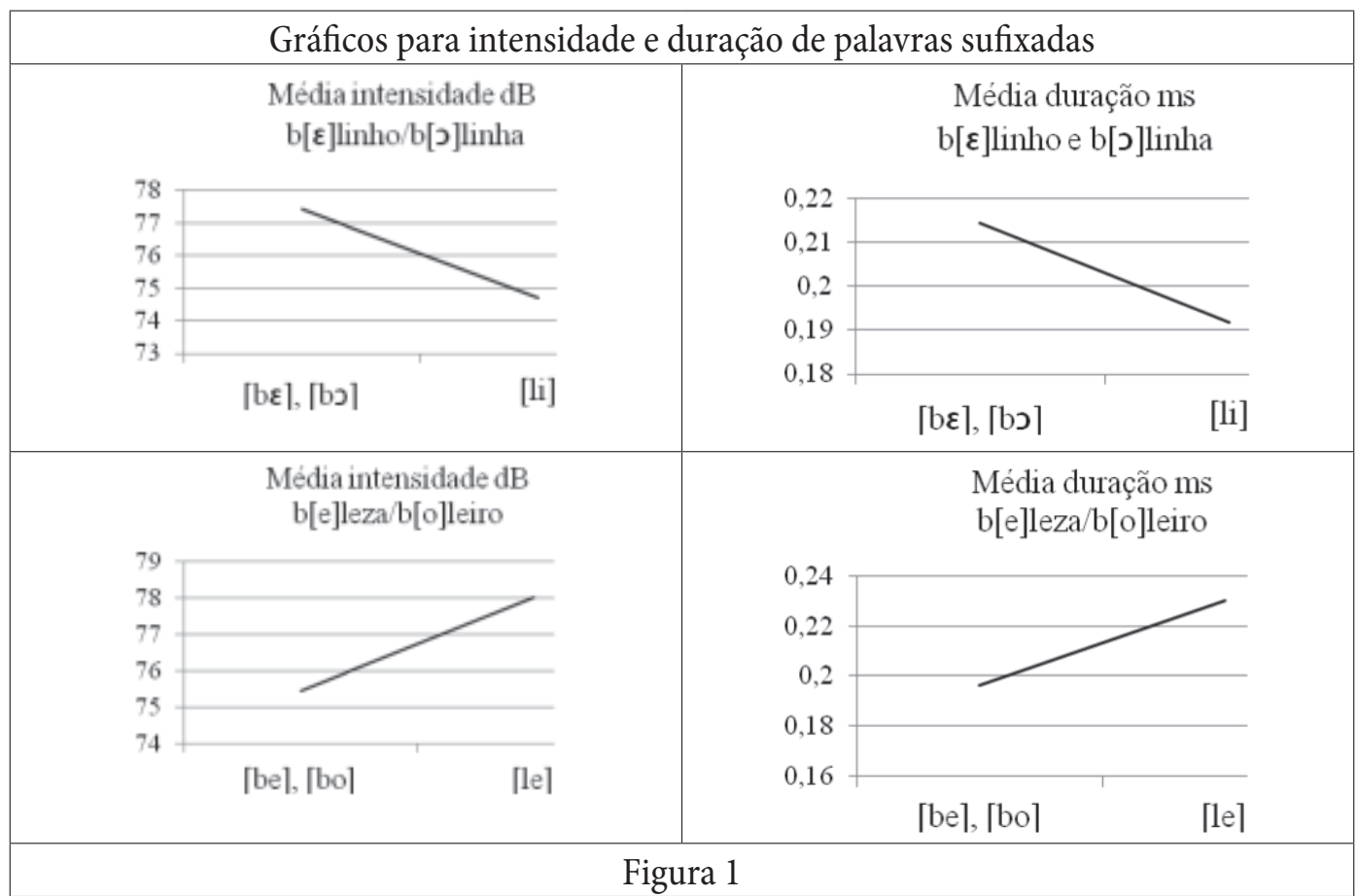

Considerando-se que o acento é uma propriedade que envolve proeminência relativa, não nos parece adequado comparar as frequências entre palavras diferentes; fixamo-nos, por isso, na comparação entre as sílabas no interior das palavras envolvidas e, só depois, analisamos contrastivamente os resultados entre as palavras de diferentes tipos de afixação. Analisadas as médias de produção das vogais envolvidas, observou-se uma queda dos indicadores, da esquerda para a direita, nas palavras do primeiro par $(b[\varepsilon]$ linho/b[J]linha), aquelas com sufixos composicionais. Isso permite identificar proeminência das sílabas com vogais médias-baixas, apesar de não licenciar a conclusão de que essas sílabas têm força igual à das sílabas tônicas dos sufixos envolvidos. Em relação ao segundo par (b[e]leza/b[o]leiro), com sufixos legítimos, ocorre o esperado: há um crescimento dos indicadores em direção à sílaba tônica.

Se essa análise fonética, por um lado, não se mostrou suficiente para corroborar a hipótese fonológica de que as palavras do primeiro par possuem dois acentos primários, por outro não permite negá-la. O que se vê, considerados os indicadores medidos nesse recorte analítico, é que sílabas con- 
tendo vogais médias-baixas caracterizam-se por proeminência que inclusive supera a das sílabas convencionalmente entendidas como tônicas. É evidente que qualquer conclusão mais contundente exige uma análise mais completa.

A análise que defendemos neste texto tem forte repercussão sobre muitos outros aspectos da morfofonologia do PB. Um deles, que vale a pena destacar aqui, é, por exemplo, o de se definir se inho e zinho são morfemas diferentes ou variantes fonológicas de um mesmo morfema. Ora, se o comportamento fonológico das bases em relação à neutralização da pretônica é idêntico para ambos, não parece haver razão plausível para apontá-los como afixos diferentes, especialmente porque a escolha de um ou de outro está fortemente influenciada por condicionadores fonológicos, preponderantemente pelo acento, conforme apontou Bisol (2010). ${ }^{12}$ Além dos fatores apontados pela autora, outros aspectos de natureza morfossintática também contribuem para sustentar a semelhança entre esses afixos. Em instrumento aplicado a 20 informantes de escolaridade média ou superior, testamos se palavras simples, como mercado e lâmpada, e palavras prefixadas por afixos composicionais ou compostas, como supermercado ou porta-lâmpada, poderiam fazer distinção pela seleção de inho ou zinho. Se se confirmasse a hipótese de que inho se junta à palavra simples, mas zinho a uma estrutura sintática (ou pós-lexical), teríamos evidência para dizer que tais afixos, numa perspectiva de gramática unidirecional - em que a morfologia precede a sintaxe -, são entradas distintas, selecionadas por nível da gramática. Essa distribuição, porém, não se confirmou, uma vez que os informantes fizeram uso indiscriminado dos alomorfes nesses contextos. ${ }^{13}$

Outro aspecto, por fim, também bastante relevante é o de se definir, uma vez considerada essa análise, o que, então, diferencia composição de afixação. A resposta para essa questão, à parte de um modelo específico de gramática, é, inicialmente, aquela que está no cerne da proposição de hierarquias prosódicas: a de que afixação e composição morfológicas devem ser vistas num plano separado do plano que lida com afixação (adjunção e incorporação) e composição prosódicas (cf. Schwindt, 2008). É evidente,

12 Essa não é, por exemplo, a conclusão de Bermúdez-Otero (2007;2013) para o espanhol, que propõe que ito e cito são sufixos distintos, que operam em diferentes níveis da gramática. $\mathrm{O}$ fato é que o sistema do espanhol não conta com vogais médias-baixas fonológicas, o que impede qualquer constatação baseada numa neutralização como a que se dá em português brasileiro.

$13 \mathrm{O}$ referido teste foi subdividido em dois, com os mesmos objetivos, mas cada um com conjuntos diferentes de 10 palavras. Se uma palavra simples, como lâmpada, constava em um teste, sua respectiva palavra composta, porta-lâmpada, aparecia no outro, evitando, assim, que os respondentes selecionassem o mesmo afixo para as duas formas sem reflexão. Cada teste foi aplicado a 10 sujeitos, totalizando 200 dados.

Organon, Porto Alegre, v. 28, n. 54, p. 137-154, jan./jun. 2013. 
porém, que a questão se torna mais complexa quando essas estruturas precisam ser comparadas, ainda, a estruturas maiores do que a palavra, como frases fonológicas ou grupos clíticos. É nesses casos que modelos seriais são chamados a mostrar a eficiência de níveis de derivação ou modelos paralelistas precisam lançar mão de restrições de alinhamento generalizado.

Independentemente, contudo, da arquitetura de gramática que se assuma, reconhecemos no processo de neutralização da pretônica importante evidência dos limites da PWd em português, o que nos permite sugerir diferentes representações para os dois grupos de exemplos apresentados em (2). A seguir, em (5), está a representação que dá conta dos exemplos em que operam bases (afixos ou radicais) que se comportam como PWds independentes - o que rotulamos como composição prosódica. Em (6), estão os casos em que há pleno isomorfismo entre PWd e palavra morfossintática (MWd) - o que se nomeia incorporação prosódica. ${ }^{14}$

$\begin{array}{ll} & {\left[[\mathrm{X}]_{\mathrm{PWd}}[\mathrm{Y}]_{\mathrm{PWd}}\right]_{\mathrm{MWd}}} \\ \text { prefixação } & p[\supset] \text { s-parto } \\ \text { sufixação } & b[\varepsilon] \text { líssimo } \\ \text { composição } & {[\varepsilon] \text { co-turismo }}\end{array}$

(6)

$\begin{array}{ll} & {[\mathrm{XY}]_{\mathrm{PWd}, \mathrm{MWd}}} \\ \text { prefixação } & p[o]_{\text {sposto }} \\ \text { sufixação } & b[e] \text { leza } \\ \text { composição } & {[\text { e]cologia }}\end{array}$

Por fim, salientamos que é papel da gramática administrar a tensão entre essas estruturas representacionais, que, em nosso julgamento, ainda que nem sempre sejam isomórficas, ensejam isomorfismo (conf. Schwindt, 2008b).

\section{Conclusão}

Neste texto, tratamos da relação entre o processo de neutralização da vogal pretônica e a formação de palavras derivadas e compostas em PB.

Partindo dos quatro casos propostos por Trubetzkoy para classificar a realização de um arquifonema, caracterizamos a neutralização em foco

14 Conforme afirmamos anteriormente, a representação prosódica completa que assumimos no caso de (5) prevê recursividade da PWd: $\left[[\mathrm{X}]_{\mathrm{PWd}}[\mathrm{Y}]_{\mathrm{PWd}}\right]_{\mathrm{PWd}, \mathrm{MWd}}$. Também a representação de (6) pode contemplar recursividade da PWd, em casos de adjunção prosódica, isto é, casos em que o afixo se liga a uma base que já é uma PWd bem formada: $\left[[\mathrm{X}]_{\sigma}[\mathrm{Y}]_{\mathrm{PWd}_{\mathrm{d}}}\right]_{\mathrm{PWd}, \mathrm{MWd}}$. Neste último caso, como mencionamos anteriormente (nota 8), há também violação a exaustividade. 
como um processo que repercute na redução do inventário fonológico, de 7 para 5 segmentos vocálicos, à semelhança do que propôs Camara Jr. Para isso, nos valemos de dialetos em que não se produzem vogais médias-baixas em posição pretônica, e assumimos que, nos dialetos em que isso ocorre, tal realização é produto de superfície, fruto de abaixamento da vogal.

Na perspectiva da Fonologia Prosódica, reiteramos uma análise em que certos afixos podem se configurar como PWds independentes, e consideramos o fato de NVP não se aplicar a esses contextos a principal evidência para essa tese. Acrescentamos à argumentação resultados de experimentos que contribuem, ainda, para caracterizar igualmente os afixos inho e zinho do ponto de vista prosódico. Enquanto entidades representacionais, PWds e MWds nem sempre são isomórficas; entendemos como tarefa de uma teoria de gramática lidar com o pareamento entre essas unidades.

\section{BIBLIOGRAFIA}

BERMUDEZ-OTERO, R. Morphological structure and phonological domains in Spanish denominal derivation. In Fernando Martínez-Gil \& Sonia Colina (eds) Optimality-theoretic studies in Spanish phonology. Amsterdam: John Benjamins, 2007, p. 278-311.

. The Spanish lexicon stores stems with theme vowels, not roots with inflectional class features. PROBUS (25)1, 2013, Mouton de Gruyter. BISOL, L. Harmonia vocálica: uma regra variável. Tese de doutorado. Universidade Federal do Rio de Janeiro. 1981. 335 p.

. Os constituintes prosódicos. In: BISOL, L. Introdução a estudos de fonologia do português brasileiro. 1 ed. Porto Alegre: EDIPUCRS, 1996. . Neutralização das átonas. DELTA, vol.19, n.2, São Paulo: EDUC, PUCSP, 2003, p.267-276.

. Mattoso Câmara Jr. e a palavra prosódica. DELTA, v. 20 n. especial, São Paulo: EDUC, PUCSP, 2004, p. 59-70.

. O diminutivo e suas demandas. DELTA, v. 26:1, São Paulo: EDUC, PUCSP, 2010, p. 59-85.

BOOIJ, G. Cliticization as a prosodic integration: the case of Dutch. The Linguistic Review, 13, 1996, p. 219-242.

BOOIJ, G.; LIEBER, R. On the simultaneity of morphological and prosodic structure. ms, Free University, Amsterdam, 1989.

CAMARA JR., J. M. Para o estudo da fonêmica portuguesa. 2 ed. Rio de Janeiro: Padrão, 1977.

CALLOU, D.;LEITE, Y. Iniciação à fonética e à fonologia. Rio de Janeiro: Jorge Zahar, 1990. 
CALLOU, D.; LEITE, Y.; COUTINHO, L. Elevação e abaixamento das vogais pretônicas no dialeto do Rio de janeiro. Organon. Revista do Instituto de Letras e Artes da UFRGS. Porto Alegre, v. 5, n. 18, p. 71-78, 1991.

INKELAS, S. Prosodic Constituency in the Lexicon. Doctoral dissertation, Stanford University, 1989.

KIPARSKY, P. Lexical morphology and phonology. In: S. Yang (ed.) Linguistic in the morning Calm. Seoul: Hanshin Publishing Co. p. 3-91, 1982. . Some consequences of lexical phonology. Phonology yearbook 2. London: Cambridge University Press, p. 85-138, 1985.

LEE, S.-H. Mid Vowel Alternations in Verbal Stems in Brazilian Portuguese. Journal of Portuguese Linguistics, Lisboa, v. 2, n. 2, p. 87-100, 2003.

. Variação linguística e representação subjacente. Estudos

Linguísticos, v. 33, p. 1311-1316, Campinas, 2004.

. Variação fonológica e contraste no sistema vocálico do PB. In:

LEE, S-H. (org.). Vogais além de Belo Horizonte. Belo Horizonte: FALE/ UFMG, 2012, p. 7-16.

LIBERMAN, M. \& PRINCE, A. On stress and linguistic rhythm.

Linguistic Inquiry, v. 8, p. 249-336. Cambridge, Mass., 1977.

MATEUS, M.; D’ANDRADE, E. The phonology of Portuguese. Oxford:

Oxford University Press, 2000.

MOHANAN, K. P. Lexical phonology. Doctoral dissertation, MIT, 1982.

. Syllable structure and lexical phonology. Phonology yearbook 2,

London: Cambridge University Press, p. 139-155, 1985.

NESPOR, M. \& VOGEL, I. Prosodic phonology. Dordrecht-Holland: Foris

Publications, 1986.

PEPERKAMP, S. Prosodic words. HIL dissertation 34. The Hague:

Holland Academic Graphics, 1997.

QUADROS, E. S.; SCHWINDT, L. C. Um estudo sobre a relação entre palavra morfológica e palavra fonológica em vocábulos complexos do português brasileiro. In: VIII Encontro do CELSUL, 2008, Porto Alegre. VIII Encontro do CELSUL: anais (CD). Porto Alegre, 2008. p. 1-18. SCHWINDT, Luiz Carlos. A harmonia vocálica em dialetos do sul do país: uma análise variacionista. Dissertação de mestrado. Porto Alegre, PUCRS, 1995.

. O prefixo no Português Brasileiro: análise morfofonológica. Tese de doutorado. Porto Alegre, Pontifícia Universidade Católica do Rio Grande do Sul, 2000.

. A regra variável de harmonização vocálica no RS. In: Bisol, L.; Brescancini, C. (Org.). Fonologia e variação: recortes do português brasileiro. Porto Alegre: EDIPUCRS, 2002, p. 161-182. 
. C. Revisitando o estatuto prosódico e morfológico de palavras prefixadas do $\mathrm{PB}$ em uma perspectiva de restrições. Alfa (ILCSE/UNESP), v. 52(2), 2008a, p. 391-404.

. Sobre a interação entre palavra fonológica e palavra morfológica no português brasileiro. In: Congreso Internacional de la Asociación de Linguistica y Filología de América Latina, 15, 2008, Montevideo, Uruguay. $C D$ do $X V$ Congreso ALFAL. Montevideo, Uruguay: Imprenta Grega, 2008b. p. 1-7.

SELKIRK, E. The syntax of words. Cambridge, Mass.: MIT Press., 1982. . Phonology and syntax: the relation between sound and structure. Cambridge, Mass.: MIT Press, 1984. The prosodic structure of function words. In: James L. Morgan and Katherine Demuth (eds.) Signal to syntax: bootstrapping from speech to grammar in early acquisition. Mahwah, NJ: Lawrence Erlbaum Associates, 1996, p. 187-213.

SILVA, M. B. As pretônicas no falar baiano: a variedade culta de Salvador. Tese de doutorado. UFRJ, 1989, 374 p.

TRUBETZKOY, N. Principles of Phonology. Traduzido do alemão por Christiane A. M. Baltaxe. University of California Press., [1939]1969. VIGÁRIO, M. The prosodic word in European Portuguese. Tese de doutorado. Lisboa, Faculdade de Letras, 2001.

VIEIRA, M. J. B.. As vogais médias postônicas: uma análise variacionista. In: BISOL, L; BRESCANCINI, C. (orgs.) Fonologia e Variação: Recortes do português brasileiro. Porto Alegre: EDIPUCRS, 2002. p. 127-159.

VIEGAS, M. C. Alçamento de vogais médias pretônicas: uma abordagem sociolinguística. Dissertação de mestrado. Universidade Federal de Minas Gerais, 1987.

WETZELS, L. Mid vowel neutralization in brazilian portuguese. Cadernos de estudos lingüísticos. n. 23, p. 19-55. Campinas: UNICAMP, 1992. . Mid-vowel Neutralization in Brazilian Portuguese Verb. Phonology 12, Cambridge Univ. Press, p. 281-304, 1995.

Recebido em: 31/03/2013; Aceito em: 18/06/2013 